\title{
From industry 4.0 to lab 4.0
}

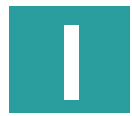

nnovations from the 'third industrial revolution' are already making a huge impact in the lab. Image $J$ is now over 20 years old and software to aid in lab work is becoming increasingly more advanced and attainable - one example can be seen in this issue, where Bates et al. have created a smartphone app for quantitation of complex images that can be used to analyze large amounts of data and in citizen science capacities. Software such as this are crucial now that a common bottleneck in research is the enormous quantity of data that can be produced by new tech - a common theme at scientific meetings is how to analyze it effectively.

These innovations are moving us into the fourth industrial revolution, or 'Industry $4.0^{\prime}$ - that is, harnessing the technological innovations of the third revolution and converging digital, biological and physical concepts in systems. One example of this was seen in work on

\section{6 ...this "biologicalization of manufacturing' is an exciting new prospect."} directed evolution of enzymes, opening up new ways to make pharmaceuticals and environmentally friendly chemicals. Frances Arnold shared the Nobel Prize in Chemistry for this in 2018. With the impact of lab work on the environment clearly a problem (as discussed in our January 2019 issue), this 'biologicalization of manufacturing' is an exciting new prospect.

Overall, Industry 4.0 promises to further our understanding of biology immensely, and enable us to revolutionize our research methods - I can't wait to see more coming across the BioTechniques news desk on this topic.

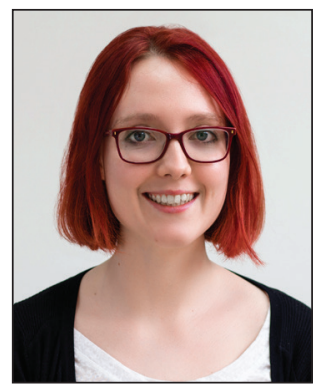

\section{Francesca Lake}

Head of Open Access Publishing, Future Science Group, Unitec House, 2 Albert Place, London, UK. f.lake@future-science.com
BioTechniques is a peer-reviewed journal dedicated to the publication of original laboratory methods, related technical tools, and methods-oriented review articles that are of broad interest to scientists engaged in basic applied life science research. Complete Instructions for Authors are available at: https://mc04.manuscriptcentral. $\mathrm{com} / \mathrm{fs}-\mathrm{btn}$, BioTechniques' website for online manuscript submission. All manuscripts should be submitted at this site.

\section{BioTechniques Staff}

Editorial, Production \& Circulation

Chairman: James Drake

Managing Director. Phil Garner

Publisher. Cheryl Wall

Head of Open Access: Francesca Lake

Managing Editor. Joseph Martin

Digital Editor. Abigail Sawyer

Head of Production: Kathryn Berry

Sales \& Business Offices

Advertising: JT Hroncich • jt@biotechniques.com

Subscriptions: Dominik March • d.march@future-science.com

Reprints: Sam Cavana • s.cavana@future-science.com

List Rental: Leela Ripton•I.ripton@future-science.com

Permissions: Adriana Gonzalez•a.gonzalez@future-science.com

\section{Editorial Board}

Bill Brizzard, Indiana University Research and

Technology Corp.

Bruce Budowle, UNT Health Science Center

Piotr Chomczynski, Molecular Research Center

Rita R. Colwell, University of Maryland-College Park and Johns

Hopkins University

Joshua J. Coon, University of Wisconsin-Madison

David Cronk, Charles River Laboratories

Manel Esteller, Spanish National Cancer Centre (CNIO)

Jeffrey Felton, Western University of Health Sciences

Erica A. Golemis, Fox Chase Cancer Center

Peter M. Gresshoff, The University of Queensland

Yoshihide Hayashizaki, RIKEN

Jörg Hoheisel, German Cancer Research Center

Pui-Yan Kwok, University of California, San Francisco

Rachael L. Neve, Massachusetts Institute of Technology

Peter J. Oefner, University of Regensburg

Stephen W. Paddock, University of Wisconsin-Madison

Scott D. Patterson, Gilead Sciences, Inc.

Leonard F. Peruski, Jr., Centers for Disease Control

George Poste, Arizona State University

John Quackenbush, Harvard School of Public Health

Joshua Rappoport, Northwestern University School of Medicine

John Rossi, City of Hope

Michel Goedert, MRC

Herbert P. Schweizer, Colorado State University

Barton Slatko, New England Biolabs

Steve S. Sommer, MEDomics, LLC

Igor Stagljar, University of Toronto

Mathias Uhlén, The Royal Institute of Technology

Timothy Veenstra, SAIC-Frederick, Inc.

Kent E. Vrana, Penn State College of Medicine

Michael Weiner, AxioMx 